\title{
Paste backfill continuous pour: Red Lake operations case study
}

\author{
J Oke RockEng Inc., Canada \\ K Hawley Evolution Mining, Canada \\ T Belem Université du Québec en Abitibi-Témiscamingue, Canada
}

A Hashemi RockEng Inc., Canada

\begin{abstract}
Cemented paste backfill (CPB) has become known as a superior secondary ground support technique and mine tailings storage method for stoping. Extensive scientific research has been conducted by the authors on CPB to provide the Red Lake operation (RLO) of Evolution Mining with an optimised backfill placement process. CPB mechanical/viscous behaviour is governed by its plasticity, the tailings particle size distribution, particle shape, mineralogical composition, water content, and the type and dosage of binder used (e.g. cement and/or supplementary cementitious material). For the CPB design, it is necessary to have a thorough understanding of the combined effects of filling rate, self-weight consolidation (volume shrinkage/settlement), and binder hydration rate for each specific paste mixture. Due to these complex factors and interactions, a rational CPB material design process was assessed to demonstrate the safety aspects related to a continuous pour. For this purpose, an extensive field monitoring program was required to quantify the CPB performance and characteristics.

There are two different ways of optimising the CPB design to maximise placement rate: (i) optimising the type and amount of binder added to the system, and (ii) optimising the CPB placement process underground. Optimisation of binder type and dosage is relatively easy as the required backfill stand-up strength is based on block dimensions, stope stability, and extraction sequencing. Optimisation of backfill placement is more difficult, as the understanding of the viscous/pseudo-plastic behaviour of the CPB is required throughout the pour. Typically, a three-stage (plug-cure-main) pouring strategy is implemented to mitigate the lack of understanding of the CPB behaviour during placement. The CPB plug (i.e. height of initial pour regime) is designed to mitigate the pressure on the backfill fence. Once this CPB plug has cured and reached the required shear strength, the backfill fence is no longer required, and the remainder of the stope void (main) can be filled. However, if the curing time of the in situ paste is accelerated due to the binder exothermic hydration process (volume shrinkage) and backfill self-weight consolidation (water drainage), it is possible to have a more aggressive pour regime provided that all the required design parameters, site procedures, company protocols, and critical controls are met.
\end{abstract}

RLO implemented instrumentation, and an early-age CPB strength testing program to evaluate whether their $C P B$ can be poured continuously or at least more aggressively. Four stopes were instrumented with total earth pressure cells (TEPCS) and piezometers to capture the pressures acting on the fill fence structures and the strengthening response of the CPB plug within the stopes. This paper summarises the results of each of the tests performed. Based on the results obtained from this study, it was concluded that RLO can safely conduct continuous CPB pours with appropriate safeguards and protocols in place. It is important to note that this paper is a summary of the CPB performance and characteristics in RLO longhole stopes and does not reflect site-specific safety procedures, protocols, and critical controls required for a more aggressive pouring regime.

Keywords: cemented paste backfill, instrumentation, total pressures, continuous pour, shotcrete fill fence 


\section{Introduction}

Backfilling is a critical component of the mining cycle for many underground mines as it provides ground support to maintain stability in active mining areas and maximises ore recovery through reduced requirement for pillars between stopes. Cemented paste backfill (CPB) is a widely used backfilling material providing efficient and rapid ground support, engineered strength properties, homogenous material properties, and environmental benefits in enabling the diversion of a portion of tailings from surface storage. However, backfill costs account for 15-20\% of the total mining cost, as stated in Yumlu (2001), at Cayeli mine for an open stoping mine. At RLO, the cost of binder in 2019 was CAD 3.8 million for the year. Binder is typically $75-80 \%$ of backfilling operations costs (Grice 1998). Due to these costs, it is important to have an efficient backfill design and process while ensuring a safe work environment.

RLO conducted an instrumentation program to quantify the change in RLO'S CPB plug characteristics throughout the pouring process in order to optimise their pour regime and determine if they could continuous pour ${ }^{1}$. To achieve this goal, the behaviour of the CPB within the stope, and the backfill loading (pressure) on the shotcrete fill fence ${ }^{2}$ needed to be captured. For this purpose, instrumentation comprised of total earth pressure cells (TEPCs, to measure total pressure, $\sigma$ ) and piezometers (to measure porewater pressure, $u$ or PWP) were installed together as a cluster so that effective stresses, $\sigma^{\prime}$, could be measured $\left(\sigma^{\prime}=\sigma-u\right)$. Each instrument cluster consisted of one piezometer and at least one TEPC. When possible, three TEPCs were installed and oriented in three mutually orthogonal axes and secured to a rigid structure (cage) as shown in Figure 1. Capturing orthogonal pressure data enables a more thorough and robust interpretation of data when CPB transitions from a fluid-like state to a more soil-like material. Identification of this transition is extremely useful in predicting whether a specific CPB recipe and pour regime will result in relatively high or low fill fence pressure conditions. All of the information and data that was collected formed the basis of the site-specific pouring procedures in addition to ensuring adequate fence designs, Factors of Safety, and potential for automated pouring, which are not discussed in this paper.
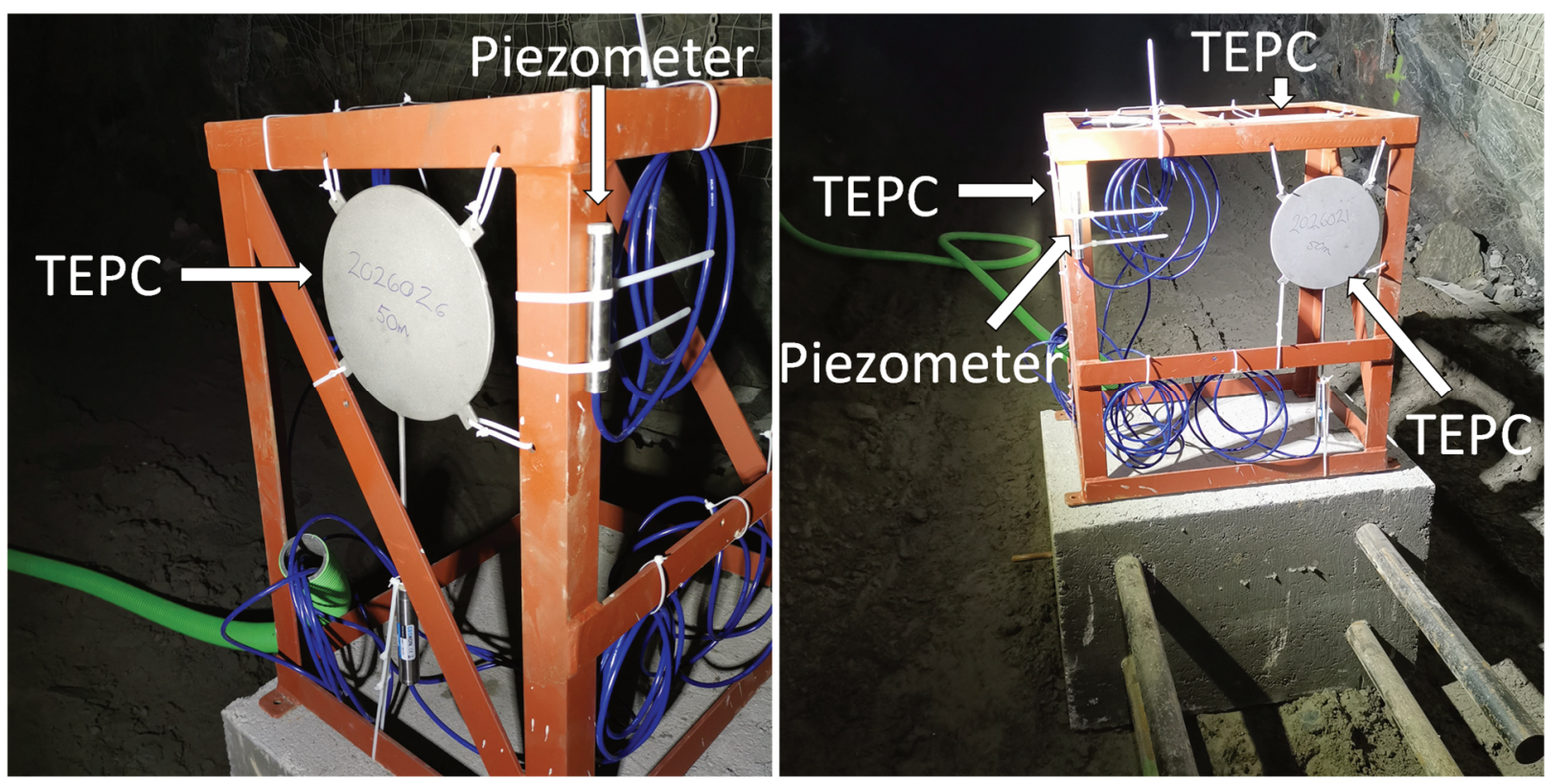

Figure 1 Instrumentation setup for the in-stope instrumentation cluster for stope 321-865-1W Blk 3

${ }^{1}$ Continuous pouring is defined as backfilling a stope in one application without stopping.

2The terminology 'barricade', 'fill fence', and 'bulkhead'” are all used within the industry to mean impermeable (generally shotcreted) backfill containment structures. However, at RLO, 'barricade' terminology is used to describe other types of barriers, so 'fill fence' will only be used within this paper. 
RLO has been using CPB since the late 1990s. The site currently has two CPB plants: the Red Lake paste plant that operates as a batch mixing process and the Campbell paste plant that is a continuous pouring system. Both plants feed various areas of the mine through an extensive underground distribution system. Prior to this study, a plug-cure-main pouring strategy was implemented on all longhole stopes. The cure time was based on a target unconfined compressive strength (UCS) of $100 \mathrm{kPa}$ used to prevent liquefaction. Based on UCS determination, conservative cure times of 36 hours and 72 hours for 9 and $5 \%$ binder, respectively, were set. Due to stope sequencing, these cure times resulted in the need to transfer back and forth between two stopes to ensure constant placement of CPB. Improving these operational delays and inefficiencies are ultimately what led to the implementation of this testing.

For this study, the TEPCs have been abbreviated to include the orientation and position of the instruments. $\mathrm{H} 1$ indicates the horizontal TEPC oriented parallel to the fence, reading pressures perpendicular to the fence (stope strike). $\mathrm{H} 2$ indicates the horizontal TEPC oriented perpendicular to the fence, reading pressures parallel to the fence (stope width).

\section{$2 \quad$ Paste backfill fill fences}

There are three different types of shotcrete fill fences used at RLO, and are known as the following:

- Mesh reinforced fence.

- Rebar reinforced fence (rebar fence).

- Muck fence.

The mesh reinforced fence is a $20 \mathrm{~cm}$ thick shotcrete arched fill fence with wire mesh embedded throughout the shotcrete and has a maximum span of $4.9 \mathrm{~m}$. The arched rebar fence consists of rebar positioned on $61 \mathrm{~cm}$ spacing, horizontally and vertically, and covered in $13 \mathrm{~cm}$ of shotcrete with a maximum span of $4.6 \mathrm{~m}$. The muck fence consists of a muck berm compacted to approximately $1.2 \mathrm{~m}$ from the back of the drift. The top $1.2 \mathrm{~m}$ of the muck fence consists of wire mesh tied to rebar embedded in the muck pile with a shotcrete thickness of $15 \mathrm{~cm}$.

The muck berm of the muck fence was constructed out of non-engineered material; therefore, the design was not engineered (i.e. not stamped). However, the testing program allowed to capture pressures acting on the structure to provide RLO with an empirical guideline for an allowable working pressure. It is important to note that the authors are not aware of an engineered muck fence; however, the consequence of a muck portion of the fence failing is low as it starts to leak prior to a major failure, allowing backfilling to stop and other safety procedures to be implemented in a timely manner.

The mesh reinforced fence and rebar fence were provided an engineered allowable design pressure as a function of the span of the fill fence. The analysis only considered the strength of the shotcrete for the design because if the shotcrete fails (i.e. crushes), then there is a possibility of paste coming through the structure. The addition of steel reinforcement (i.e. mesh or rebar embedded in the shotcrete) does increase the capacity of the fence and reduces the magnitude of potential failures (i.e. the reinforcement keeps the structure together). The increase in capacity was taken as an additional design Factor of Safety, and the reduction in the magnitude of the failure was considered for exclusion zone recommendations, although not described in this paper.

The design capacities of the fill fence will not be included within this paper as those fences were designed by third party companies. However, it was estimated that the lowest allowable design pressure for the tested fill fences in the study was about $86 \mathrm{kPa}$ for the rebar fence (for the respective tested span), and the empirical upper limit for the muck fence was found to be around $50 \mathrm{kPa}$. It is important to note that the allowable design pressure is not the capacity of the fence, but a threshold pressure that requires backfilling to stop (i.e. includes a Factor of Safety). 


\section{$3 \quad$ Paste strength}

At RLO, the plug was either made of $5 \%$ binder or $9 \%$ binder (30-40\% class C fly ash, $60-70 \%$ general use Portland cement). At the site, $9 \%$ binder is primarily used if there are planned inverse stopes underneath the plug (i.e. underhand stopes) or if stope sequencing needs to be sped up. This high binder content is used to limit potential CPB dilution for both the endwall or if overbreak occurs when mining the block below. The $5 \%$ binder for the plug is used for the remainder of the stopes. For the main pour (remainder of the stope void), 3 or $5 \%$ binder is used depending on endwall strength requirements and sequencing. However, only $3 \%$ binder (main pour) was used in this study to represent a worst-case scenario pouring regime. Early-age strength testing was conducted on the plug CPB mixtures. An example of the early-age strength samples is shown in Figure 2 for $9 \%$ binder. At two hours of cure time, the samples are no longer in a liquid state but are very soft to self-support and cannot undergo a compression test. This is an indication that at two hours, shear strength has started to develop. At six hours, the shape of the casting cylinder was maintained, but the samples are still too soft to undergo a compression test.
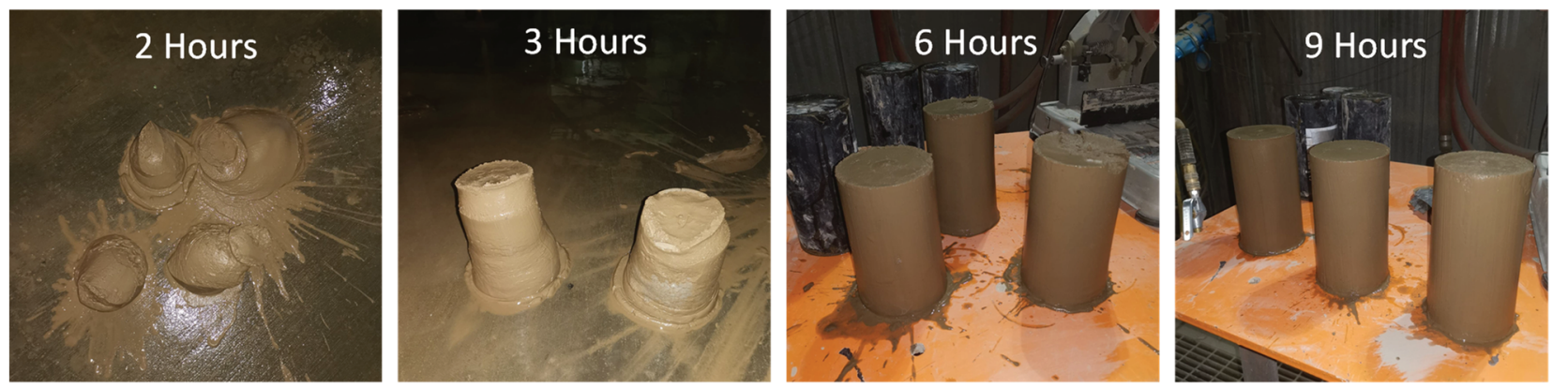

Figure 2 Early-age strength of 9\% binder samples from stope 512-595-1E Blk 3. Samples at cure time lower than six hours were not tested

These tests were conducted to find the cure time at which the CPB is able to resist liquefaction (cyclic failure of softening). The minimum UCS required to resist liquefaction is $37 \mathrm{kPa}$ based on laboratory work by Le Roux et al. (2004). Indeed, Le Roux et al. (2004) found that a CPB cured for 12 hours and having a UCS of approximately $37 \mathrm{kPa}$ could not be liquefied by triaxial cyclic loading at the highest load levels achievable in the hydraulic test frame of the laboratory setting. This result is in general agreement with Belem et al. (2013), for a seismic magnitude of six or less. From the results of the site testing, $9 \%$ binder was able to reach $37 \mathrm{kPa}$ by 17 hours, and $5 \%$ binder was able to reach $37 \mathrm{kPa}$ by 20 hours; however, for stope 321-865-1W Blk 3, the lower bound of the strength curve from testing did not reach $37 \mathrm{kPa}$ until 26 hours.

\section{$4 \quad$ Instrumented stopes}

For this study, four different test stopes were investigated: two tests had shotcrete muck fences and two had shotcrete rebar fences, one of each with a $5 \%$ binder plug and the others with a $9 \%$ binder plug. Unfortunately, it was not possible to determine (i.e. directly measured) the fill heights within the stope during the pours. Therefore, all fill heights were required to be inferred.

\subsection{Stope 321-865-1W BLK 3}

Stope 321-865-1W BLK3 was the first stope monitored at RLO. The stope is $16.4 \mathrm{~m}$ high, $23.5 \mathrm{~m}$ long, and $3 \mathrm{~m}$ wide from hanging wall (HW) to footwall (FW) with a dip of $\sim 65^{\circ}$. The muck fence barricade was constructed in a drift that was $3 \mathrm{~m}$ wide and $3.4 \mathrm{~m}$ high. Instruments on the muck fence were positioned approximately $3 \mathrm{~m}$ away from the brow and the in-stope instrument cluster was positioned $6.4 \mathrm{~m}$ as shown in Figure 3 . The binder content for the plug was $5 \%$. The total time and pour time required for the stope were 53 hours and 35 hours, respectively. Table 1 provides a summary of the pour, flushes, and associated cure periods.

The initial pour started at 9:16 on 11 June 2020. The start time corresponds with an initial decrease in temperature (caused by the flush), as shown in Figure 4. It is estimated that shortly after 12:00 the first 
instrument (TEPC 511, horizontal H2-axis) was covered in backfill. Horizontal TEPC (TEPC-H2) was positioned at approximately $1.0 \mathrm{~m}$ above the bottom of the surveyed CMS stope, which works out to a fill rate of $0.4 \mathrm{~m} / \mathrm{h}$. It is important to note that typically the initial pour fills at a faster rate as the base of the pour has some remaining muck and in this case the muck berm extends into the stope. The backfill continues to pour until 14:55, based on operator notes. The drop in pore pressure (dissipation) at 14:00 is an indication that the backfill is able to drain freely and/or it is self-weight consolidating. Following the pore pressure drop, the horizontal pressure (TEPC-H2) dropped while the vertical pressure (TEPC-V) remained constant, indicating non-hydrostatic conditions.

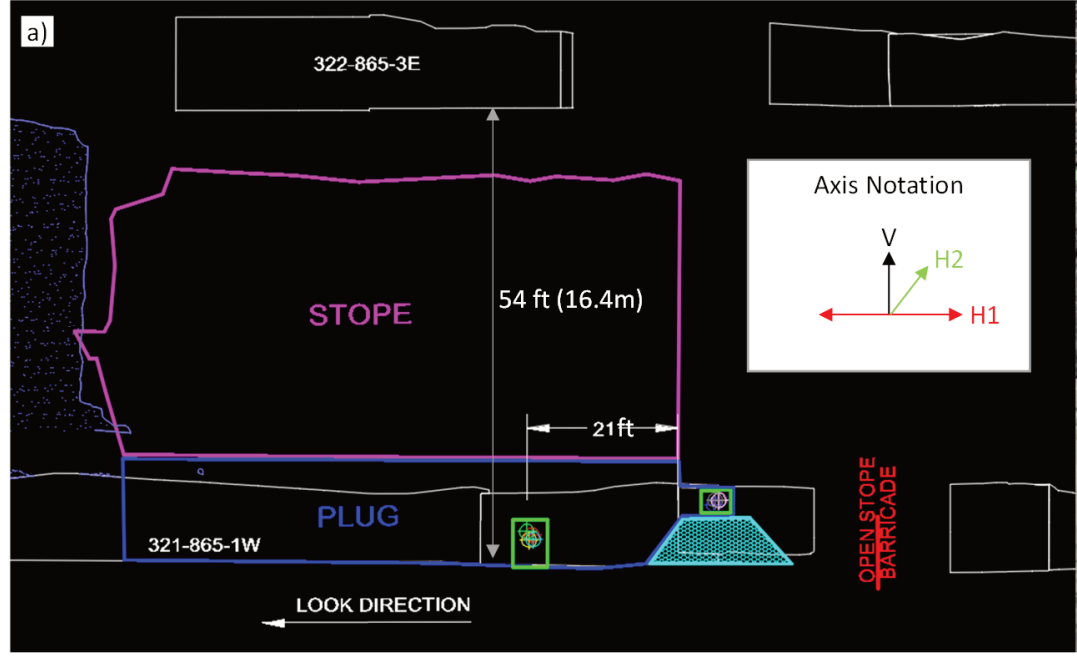

(a)

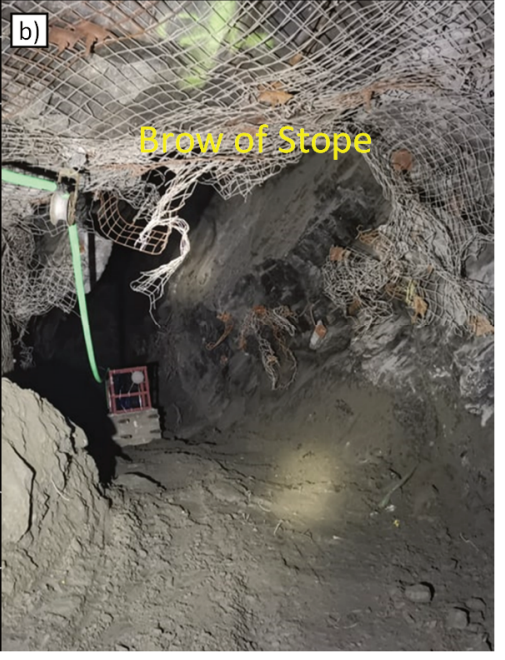

(b)

Figure 3 321-865-1W Blk 3 instrumentation and fence location. (a) Illustration of clusters with reference to the brow of the stope; (b) Position of in-stope instrument cluster. Note: Instruments were installed within the stope remotely and picture was taken from the 'no personnel entry' location

Table 1 Summary of backfilling operation. Start and end time of pours and flushes were based on underground operator logs

\begin{tabular}{|c|c|c|c|c|}
\hline Pour & $\# 1$ & \#2 & $\# 3$ & $\# 4$ \\
\hline Start & 6/11/2020 9:16 & $6 / 11 / 202021: 02$ & 2020-06-12 8:34 & 2020-06-13 8:08 \\
\hline End & $6 / 11 / 202014: 55$ & 6/12/2020 3:00 & $2020-06-132: 30$ & $2020-06-13$ 14:21 \\
\hline Flush & $6 / 11 / 2020$ 15:15 & $6 / 12 / 20203: 15$ & $2020-06-132: 50$ & 2020-06-13 14:35 \\
\hline Pour time (h) & 5.7 & 6.0 & 17.9 & 6.2 \\
\hline Cure time (h) & 6.1 & 5.6 & 5.6 & - \\
\hline
\end{tabular}

Based on a fill rate of $0.4 \mathrm{~m} / \mathrm{h}$, the expected measured vertical pressure on TEPC-V (no. 512) is $13.3 \mathrm{kPa}$. The actual measured vertical pressure is approximately $10 \mathrm{kPa}$. It should be recalled that $10 \mathrm{kPa}$ of pressure is equivalent to $0.5 \mathrm{~m}$ of geostatic pressure assuming a backfill unit weight of $20 \mathrm{kN} / \mathrm{m}^{3}$. This discrepancy between the expected pressure and the measured pressure could be due to geometric constraints. The cross-sectional area at the bottom of the stope was found to be $86.6 \mathrm{~m}^{2}$. The total plug volume was estimated at $201 \mathrm{~m}^{3}$. This results in a fill height of $2.3 \mathrm{~m}$, whereas the instruments were only indicating $\sim 1.7 \mathrm{~m}$. This difference could be caused by the relative accuracies of estimated geometries and muck berm. This interpretation of the results confirm that the instrumentation is behaving as expected. 


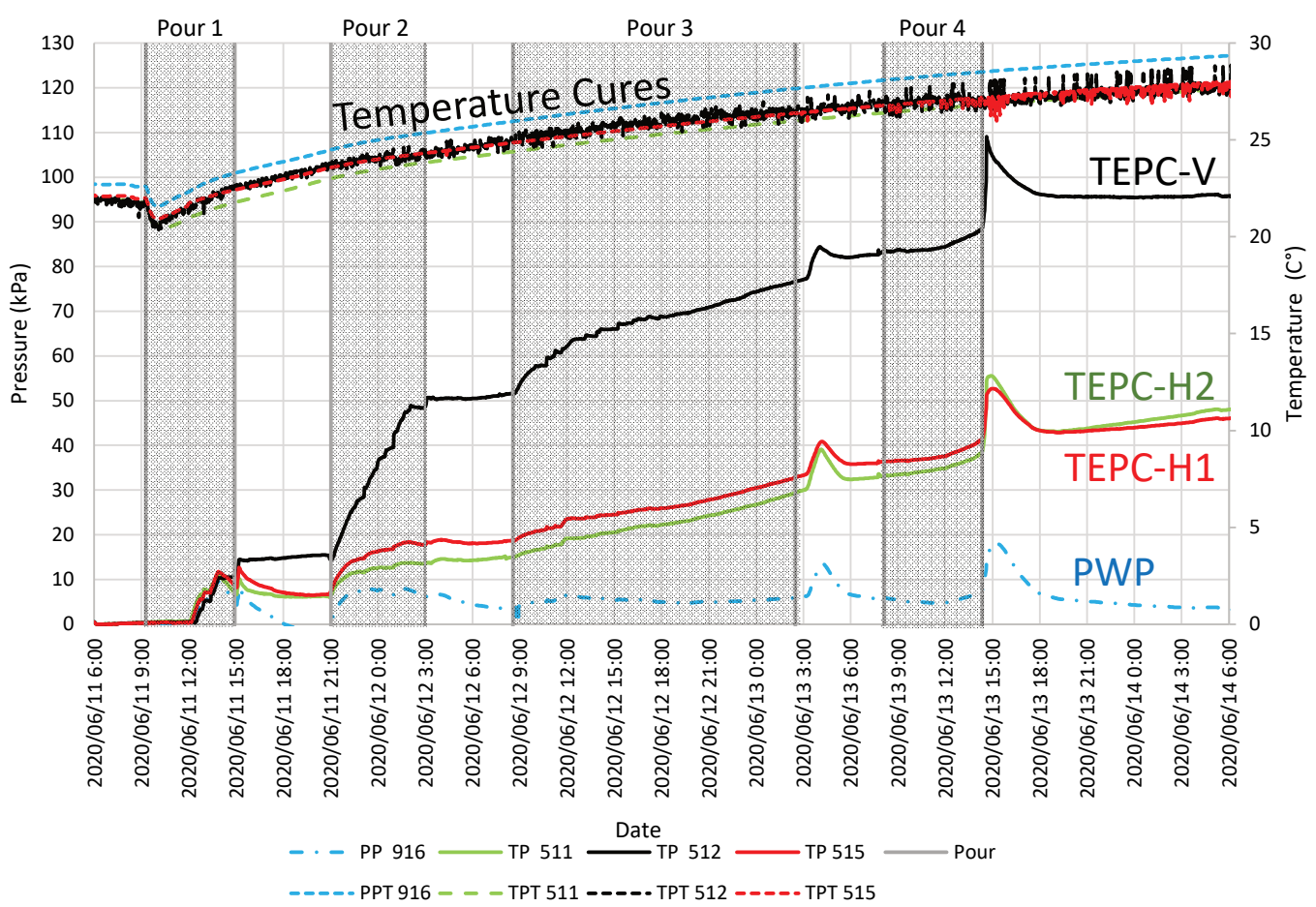

Figure 4 In-stope instrument cluster response of stope 321-865-1W BLK3

At 15:15 on 11 June 2020 there was a spike of pressure caused by a flush. Each instrument saw an increase of $4 \mathrm{kPa}$. The cross-sectional area was approximately $26.4 \mathrm{~m}^{2}$. For a spike of pressure of $4 \mathrm{kPa}$, a volume of $5.4 \mathrm{~m}^{3}$ would have had to be added to the backfill to increase the backfill height by $0.2 \mathrm{~m}$. This displaced volume agrees with the typical flush size of $6 \mathrm{~m}^{3}$. The increase in vertical pressure between 14:00 and 15:15 is explained by a 'lava' type flow as previously captured by Grabinsky et al. (2014), as shown in Figure 5a. The paste was building up in an area of the stope that did not influence the instrument. Once the flush occurred, the paste flowed towards the instrument increasing all pressure readings, including the pore pressure. This 'lava' type flow occurred previously in smaller steps at 13:00.

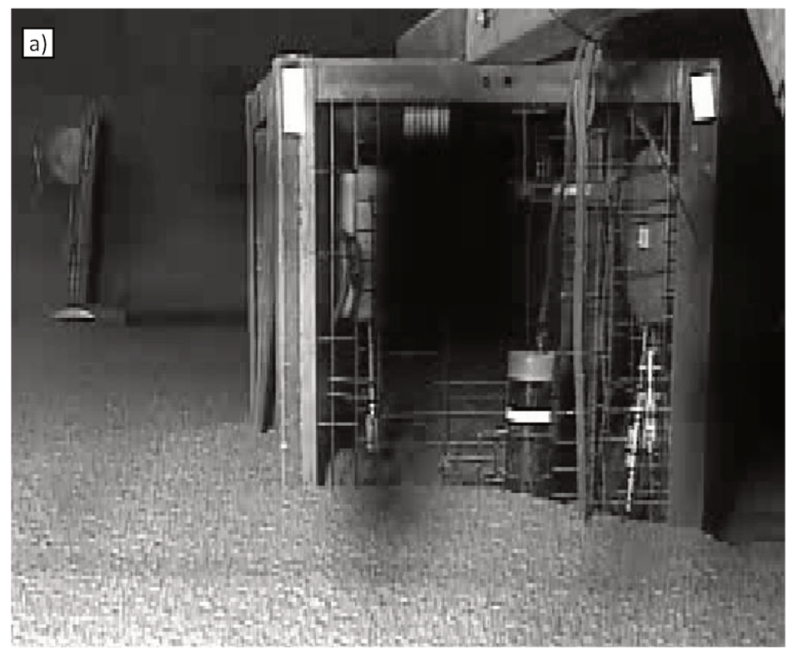

(a)

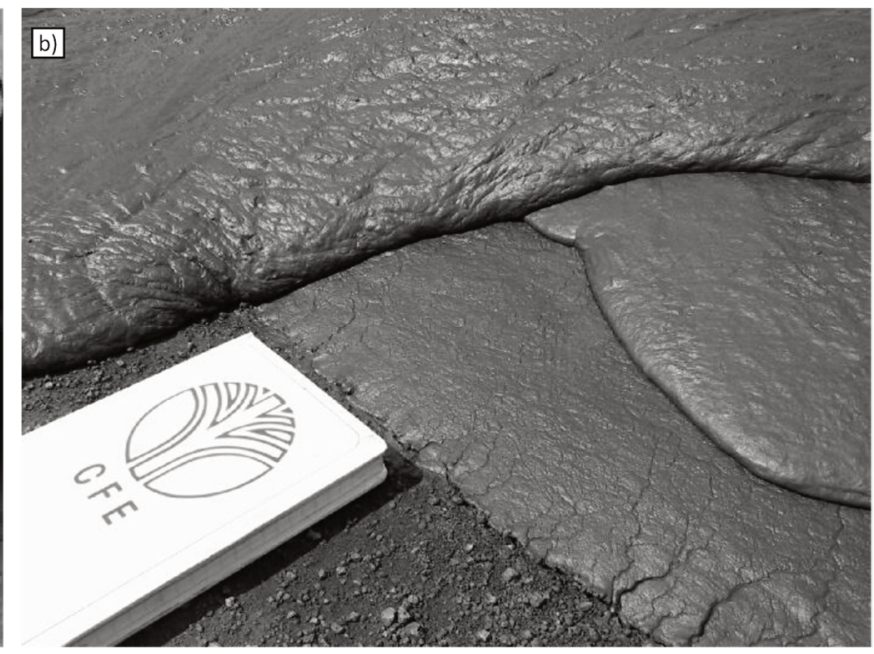

(b)

Figure 5 Image of 'lava' type flow. (a) CPB on the deposition surface and into an instrumentation cluster (modified after Grabinsky et al. 2014); (b) Surface paste tailings disposal (modified after Theriault et al. 2003) 
Figure 4 also shows that the backfill is draining and the water pressure is dropping/dissipating after the first pour and falls below the original ambient air pressure, which is known to occur. This result is an indication that effective stresses are building up. Note that the piezometer measurement is only reliable as long as the suction does not exceed $20 \mathrm{kPa}$ (the typical air entry value of the piezometer tip, at which point you get cavitation and air bubbles form).

The second pour started at 21:02 on 11 June 2020. The measured in-stope vertical pressure (TEPC-V) increased at a constant rate throughout the six-hour pour, reaching a final pressure of $50.5 \mathrm{kPa}$. This additional vertical pressure is equivalent to $1.8 \mathrm{~m}$ of geostatic pressure, corresponding to a fill rate of $0.29 \mathrm{~m} / \mathrm{h}$. Based on the cross-section area of $90.8 \mathrm{~m}^{2}$ and volume added of $193 \mathrm{~m}^{3}$, the expected increase in height was $2.1 \mathrm{~m}$.

The in-stope horizontal pressures (TEPC-H1, TEPC-H2) initially increase at the same rate as the vertical pressure (TEPC-V), but the horizontal pressure increases slow after 30 minutes and finally plateau after 4 hours. The final horizontal pressure (TEPC-H2) is $14.3 \mathrm{kPa}$ in the transversal span (green line) and $18.1 \mathrm{kPa}$ (TEPC-H1) along the longitudinal direction (red line). The piezometer (PWP) records an initial spike of pressure to $8 \mathrm{kPa}$ for the first 1.5 hours, after which the pressure slowly decreases to $5 \mathrm{kPa}$ (three hours after the pour is finished) as shown in Figure 4 . The incremental jumps in vertical pressure, and to a lesser extent, surges in horizontal pressure are hypothesised to be caused by the 'lava-like' flow of the paste.

The instrument cluster on the fill fence records the backfill reaching the horizontal TEPCs ( $\mathrm{H} 1$ and $\mathrm{H} 2)$ at 23:10, 2.1 hours after the start of the second pour, as shown in Figure 6. The difference between the top of the instrument of the in-stope cluster and the lowest horizontal instrument on the barricade cluster is $1.3 \mathrm{~m}$. It is estimated that $0.77 \mathrm{~m}$ of CPB was placed above the top instrument of the in-stope cluster, based on the increase of $15.4 \mathrm{kPa}$ of pressure. Therefore, the fill rate works out to be $0.25 \mathrm{~m} / \mathrm{h}$, which is slightly less than the calculated rate based on the in-stope cluster readings. However, the spike of pressure at the end of the pour is equivalent to $0.2 \mathrm{~m}$ of additional CPB (possible 'lava-like' flow). This increases the fill rate to $0.30 \mathrm{~m} / \mathrm{h}$, which agrees with the in-stope measurements.

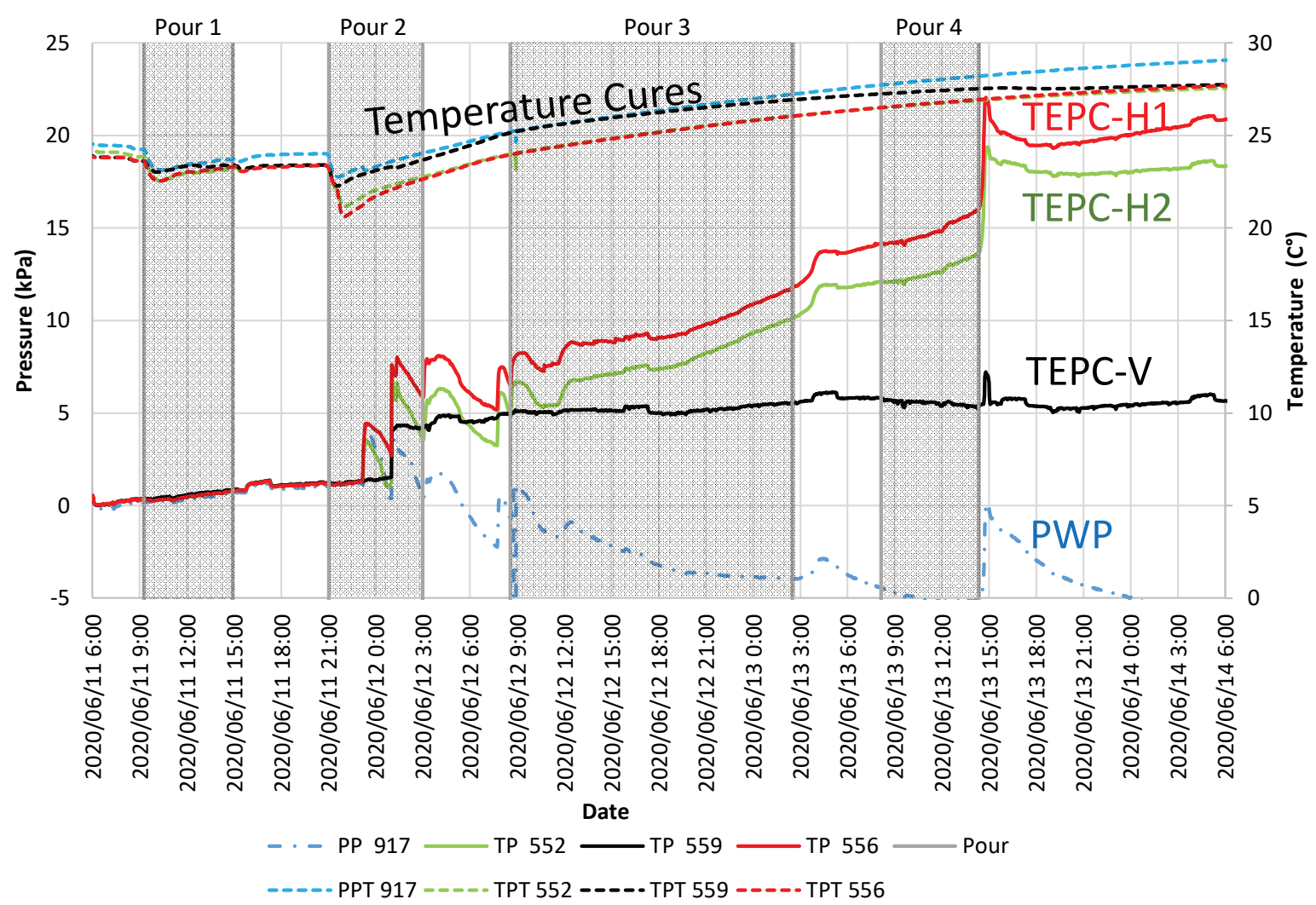

Figure 6 Fill fence instrument cluster response of stope 321-865-1W BLK3 
Figure 6 indicates that the pressure applied to the two vertically oriented TEPCs (measuring the horizontal total pressures $\mathrm{H} 1$ and $\mathrm{H} 2$ ) occurs in two different spikes or waves. These spikes correspond to some of the incremental jumps seen in the in-stope cluster. The first spike, on 2020/06/11 at 23:00, increases by 2.5 and $3 \mathrm{kPa}$ for the transversal span (TEPC- $\mathrm{H} 2$, green line) and longitudinal direction (TEPC-H1, red line), respectively. The piezometer (PWP) sees a similar spike which dissipates to zero by 1:00, right before the next spike of pressure. The TEPC-H2 instrument sees a similar decrease in pressure (i.e. returning to pre-spike pressure). The TEPC-H1 instrument reduces to $1.5 \mathrm{kPa}$ right before the next spike in pressure.

The second spike of pressure for the horizontal pressures (TEPCs $\mathrm{H} 1$ and $\mathrm{H} 2$ ) results in a 5 to $6 \mathrm{kPa}$ increase which then continues to dissipate until the end of the pour. The vertical pressure (TEPC-V) measurement sees a $2.5 \mathrm{kPa}$ pressure spike, which increases by $1 \mathrm{kPa}$ throughout the remainder of the pour and one hour after. There is a third spike of pressure at 8:00, which is interpreted to have been caused by the flush, as there is an increase in the porewater pressure (PWP), and little increase to the vertical stress measurement.

The fourth and final pour started at 8:08 on 13 June. This pour finished by $14: 21$, completely filling the 321-865-1W BLK3 stope. Figure 4 shows that during the fourth pour, the in-stope TEPC-V increases by only $5 \mathrm{kPa}$ during the fill, compared to the expected $68 \mathrm{kPa}$ increase if the backfill was hydrostatic. Therefore, only $7 \%$ of the potential pressure was transferred to the TEPC- $V$, while the remaining pressure was distributed to the side walls through internal arching effects. The flush at the end of the pour caused a $20 \mathrm{kPa}$ spike on the TEPC-V pressure measurement and 12 to $17 \mathrm{kPa}$ for the horizontal stress measurements (TEPCs $\mathrm{H} 1$ and $\mathrm{H} 2$ ). The flush caused the pressure spike, as the PWP saw a spike of $15 \mathrm{kPa}$.

Figure 6 shows that during the fourth pour, the horizontal pressure acting on the instruments (TEPCs H1 and $\mathrm{H} 2$ ) located on the fill fence increased by only $2 \mathrm{kPa}$. The flush at the end of the pour caused a $6 \mathrm{kPa}$ spike on the horizontal pressure measurements (TEPCs $\mathrm{H} 1$ and $\mathrm{H} 2$ ) and a $3 \mathrm{kPa}$ spike on the vertical pressure measurement (TEPC-V). Once again, these pressures are much lower than the potential hydrostatic pressure that would be implied from the fluid pressure of additional not cured CPB.

The instrumentation data were collected for an additional 28 days after the last pour. During this time, the instruments show generally stabilised pressures with the exceptions of a spike of pressure caused by a seismic event (moment magnitude of -1.2) from the region (approximately $50 \mathrm{~m}$ ). The unique finding from this test stope is that the highest pressures were associated with seismic events or wall closures, rather than backfilling alone, resulting in a maximum $14 \mathrm{kPa}$ spike in pressure (TEPC-H1). The spike of pressure dissipated by $7 \mathrm{kPa}$ over the next five days.

\subsection{Stope $260-876-1$ BLK1}

Stope 260-876-1 BLK1 was the second stope being monitored during the monitoring program at RLO. The stope is $20.6 \mathrm{~m}$ high, $22.7-26.5 \mathrm{~m}$ long, and $2.4-3.4 \mathrm{~m}$ wide from $\mathrm{HW}$ to $\mathrm{FW}$ with a dip of $\sim 75^{\circ}$. The rebar-reinforced shotcrete fill fence was constructed in a drift that is approximately 4.2 wide and $3.4 \mathrm{~m}$ high. The fill fence is positioned $2.1 \mathrm{~m}$ from the brow. The total time and pour time required for the stope were 51 and 41 hours, respectively. The unique finding from this test stope is that this pour had the least operational downtime, and the instrumentation captured significant thermal contraction after the completion of the pour. The detailed instrumentation results of this test stope are presented in Oke et al. (2021).

\subsection{Stope 512-595-1E BLK3}

Stope 512-595-1E BLK3 was the third stope being monitored during the monitoring program at RLO, the second to be tested on the muck fence, and the first to be poured with $9 \%$ binder ( $36 \%$ class C fly ash, $64 \%$ cement) for the plug region. Stope 512-595-1E BLK3, as shown in Figure 7, is $24 \mathrm{~m}$ high, 13-21 m long, and 3.4-5.0 m wide from $\mathrm{HW}$ to $\mathrm{FW}$ with a dip of $\sim 60^{\circ}$. The muck fence barricade was constructed in a drift that is approximately $5.0 \mathrm{~m}(16.40 \mathrm{ft})$ wide and $5.0 \mathrm{~m}$ high. The muck fence barricade was positioned $\sim 1 \mathrm{~m}$ from the brow. The total time and pour time required for the stope were 87 and 58 hours, respectively. Table 2 provides a summary of the pour, flushes, and associated cure periods. 


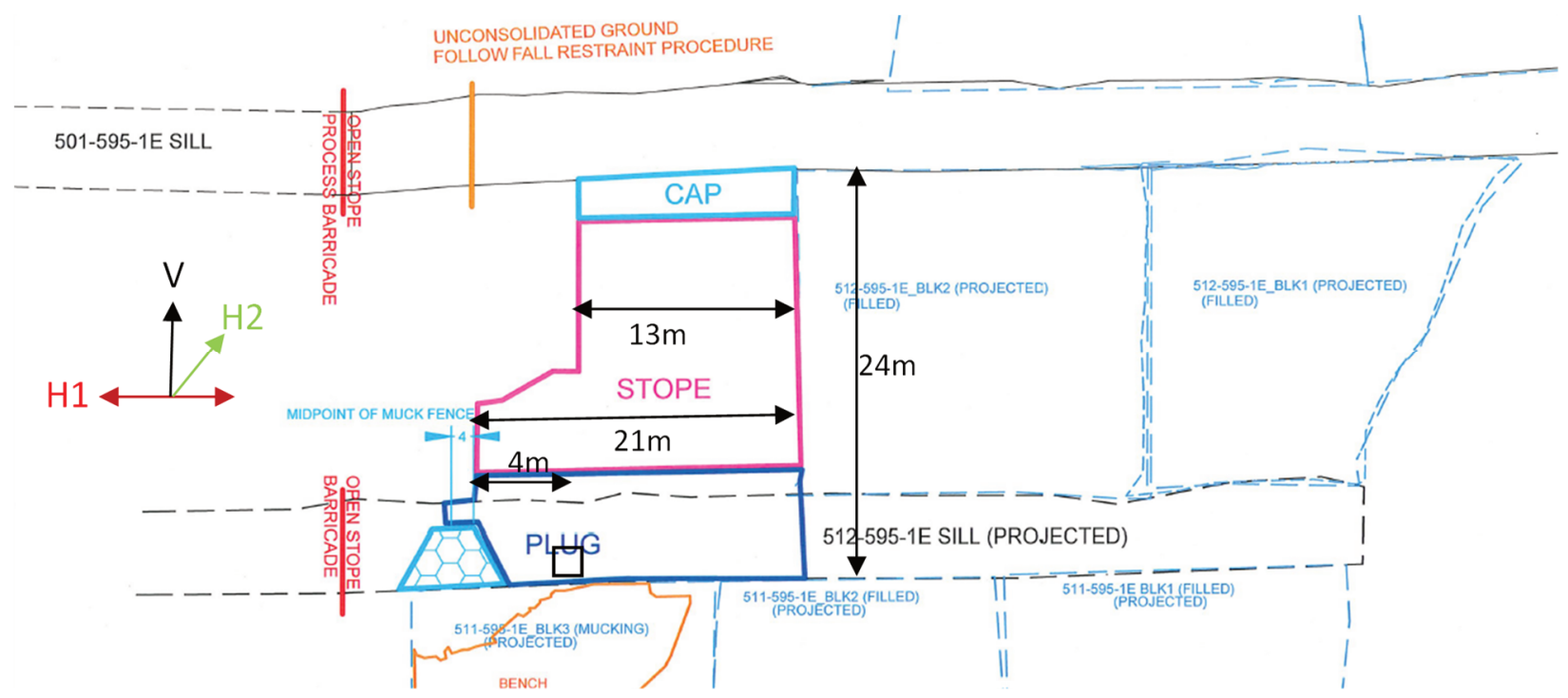

Figure $7 \quad 512-595-1 E$ Blk3 instrumentation and muck fence location with stope dimensions

Table 2 Summary of backfilling delivery. Start and end time of pours and flushes were based on underground operator logs

\begin{tabular}{lllllll}
\hline Pour & $\# \mathbf{1}$ & $\mathbf{\# 2}$ & \#3 & \#4 & \#5 & \#6 \\
\hline Flush & $9 / 23 / 2020$ & $9 / 24 / 2020$ & - & $9 / 26 / 2020$ & $9 / 26 / 2020$ & $9 / 27 / 2020$ \\
& $21: 35$ & $22: 35$ & & $0: 50$ & $21: 40$ & $7: 35$ \\
\multirow{3}{*}{ Start } & $9 / 23 / 2020$ & $9 / 25 / 2020$ & $9 / 25 / 2020$ & $9 / 26 / 2020$ & $9 / 26 / 2020$ & $9 / 27 / 2020$ \\
& $23: 30$ & $0: 30$ & $12: 55$ & $2: 05$ & $23: 05$ & $9: 00$ \\
End & $9 / 24 / 2020$ & $9 / 25 / 2020$ & $9 / 25 / 2020$ & $9 / 26 / 2020$ & $9 / 27 / 2020$ & $9 / 27 / 2020$ \\
& $22: 00$ & $10: 30$ & $21: 30$ & $9: 00$ & $3: 05$ & $14: 45$ \\
\multirow{2}{*}{ Flush } & $9 / 24 / 2020$ & $9 / 25 / 2020$ & $9 / 25 / 2020$ & $9 / 26 / 2020$ & $9 / 27 / 2020$ & $9 / 27 / 2020$ \\
& $22: 40$ & $11: 15$ & $22: 50$ & $9: 40$ & $3: 25$ & $15: 00$ \\
Pour (h) & 22.5 & 10.0 & 8.6 & 6.9 & 4.0 & 5.8 \\
Cure (h) & 2.5 & 2.4 & 4.6 & 14.1 & 5.9 & - \\
\hline
\end{tabular}

The plug pour started at 23:30 on 23 September 2020. The start time corresponded with a decrease in temperature, as shown in Figures 8 and 9 . It is estimated that at approximately 1:00 on September 24, the lowest height in-stope instruments were covered in backfill (Figure 8). TEPC 2026021 (TEPC-H1) is the lowest instrument in the in-stope cluster. Indeed, TEPC-H1-021 is positioned approximately $1.0 \mathrm{~m}$ off the muck base within the stope, which works out to a fill rate of $0.7 \mathrm{~m} / \mathrm{h}$. The initial pour fills had a fast rate at the base of the stope due to the placement of additional muck within the stope to increase the fill rate (i.e. to promote higher than typical pressure on the barricade). The lowest instrument on the fill fence (TEPC 2026020, TEPC-H1-020) was $2.6 \mathrm{~m}$ above the lowest instrument on the in-stope cluster. At 9:15 on September 24, there was a sudden increase of $0.3 \mathrm{kPa}$ of measured pressure (Figure 9), which is equivalent to $15 \mathrm{~mm}$ of CPB (assuming a bulk unit weight of $20 \mathrm{kN} / \mathrm{m}^{3}$ ). It is assumed that the paste had reached the instrument at this point in time, resulting in an average fill rate of $0.32 \mathrm{~m} / \mathrm{h}$.

The distance between the top instrument TEPC-V (measuring vertical pressure) of the in-stope cluster and the lowest instrument on the fill fence cluster was $2.4 \mathrm{~m}$. This results in a potential pressure of $48.4 \mathrm{kPa}$, but the actual pressure measured was $46.5 \mathrm{kPa}$. The difference in pressure is equivalent to a $\sim 10 \mathrm{~cm}$ difference in height of CPB. Therefore, the instrument is still measuring $100 \%$ of the potential vertical pressure, and an indication that the instrument is working properly. 


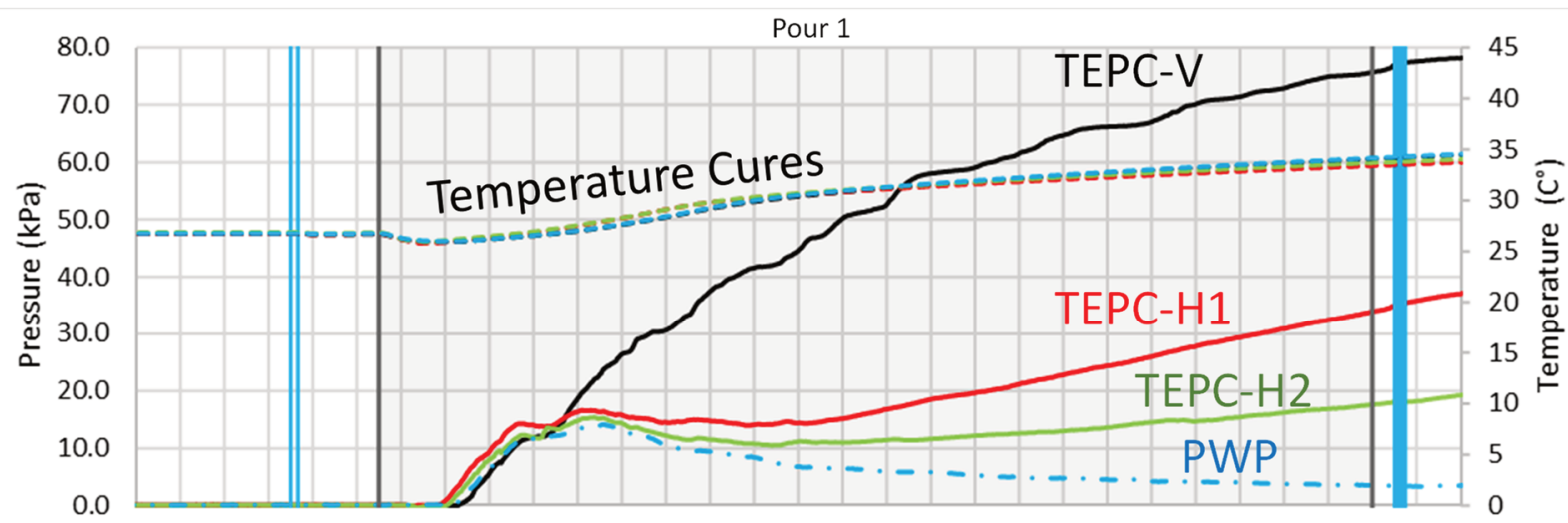

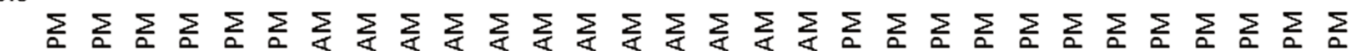

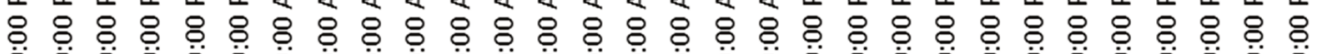

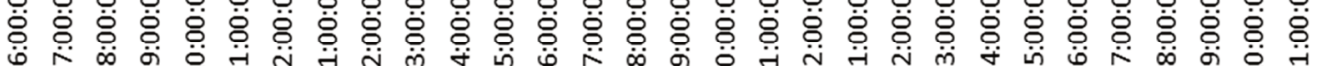

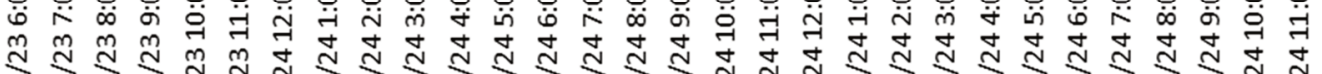

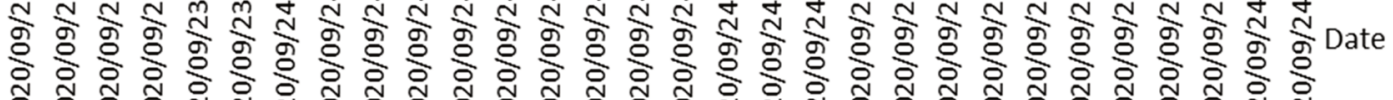

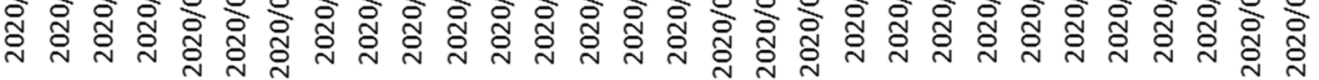

\begin{tabular}{|c|c|c|c|}
\hline - TEPC-V-2026027 & - TEPC-H1-2026021 & $\longrightarrow$ TEPC-H2-2026026 & $-\cdots$ - PP-Instope-2026362 \\
\hline $\begin{array}{l}\text { - POUR } \\
---- \text { Temp -H2-2026026 }\end{array}$ & $\begin{array}{l}\Longrightarrow \text { FLUSHES } \\
---- \text { Temp -PP-2026362 }\end{array}$ & -----Temp -V-2026027 & -----Temp -H1-2026021 \\
\hline
\end{tabular}

Figure 8 The in-stope instrument cluster response to the plug pour of stope 512-595-1E BLK3

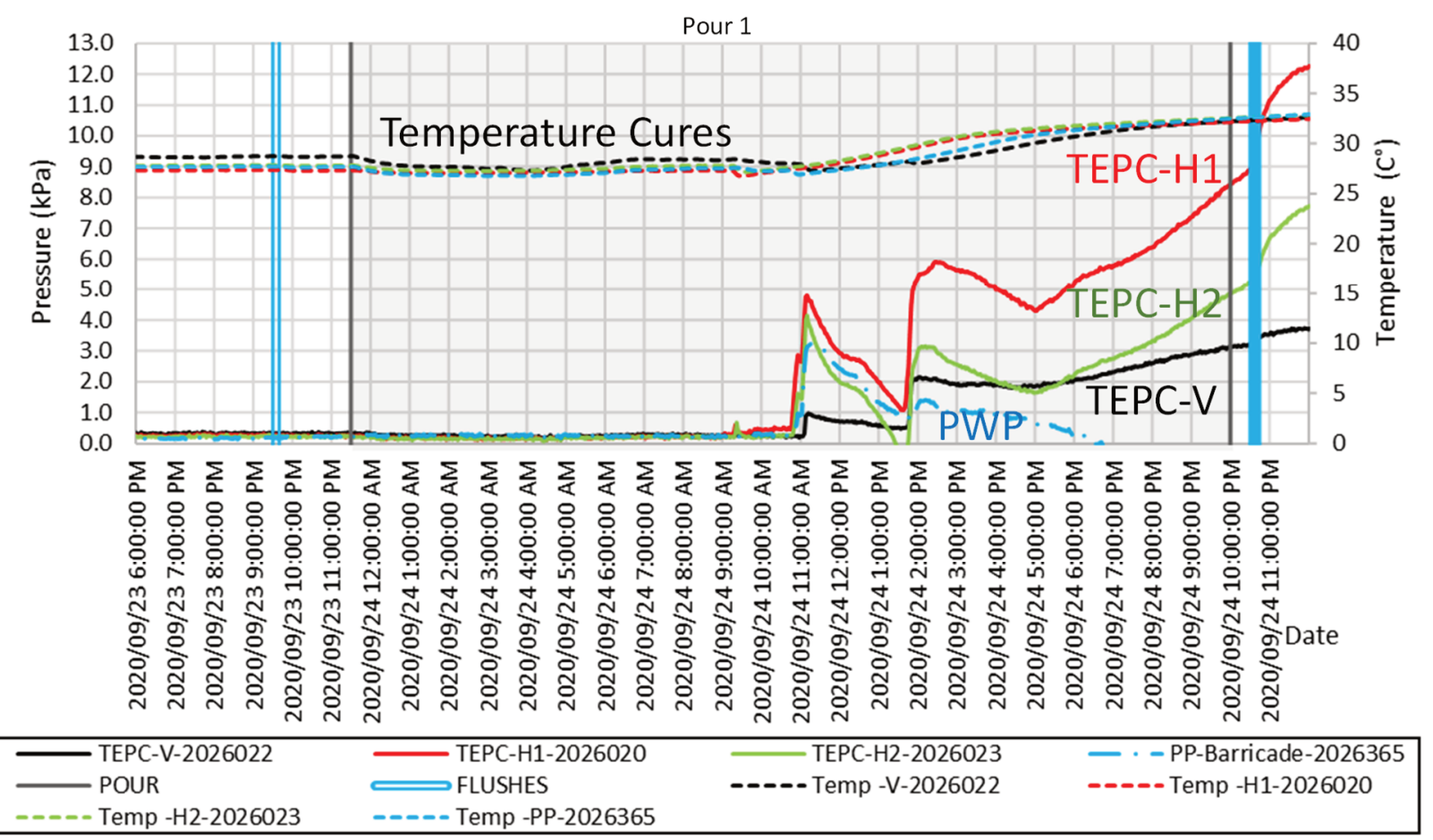

Figure 9 Fill fence instrument cluster response to the plug pour of stope 512-595-1E BLK3

Figure 8 shows that the porewater pressure (PWP) started to decrease within the stope 1.5-2.5 hours after the in-stope instruments were covered in CPB. This means that non-hydrostatic pressure started to develop within the stope 2.5 hours after the in-stope instrumentation was covered in CPB. This is an indication that the backfill had transitioned to a soil-like material with shear strength and shear stiffness development, which then developed at-rest lateral earth pressure conditions $\left(\mathrm{K}_{0}\right)$. The at-rest lateral earth pressure coefficient $\mathrm{K}_{0}$ at the end of the first pour was found in the range of $0.20-0.42$. The $K_{0}$ range can vary widely during the plug pour. The $\mathrm{K}_{0}$ observed here is empirically low; however, it is still within range measured by the authors at 
other sites. If the $K_{0}$ was any lower, there may be concern that the horizontal pressure measurements could be incorrect.

Figure 9 shows the results from the instrument cluster installed on the fill fence. The initial increase of $0.3 \mathrm{kPa}$ of pressure was assumed to be the CPB reaching the instrument at 9:15 on 24 September 2020. The next increase in pressure did not occur until 11:00 when there was a sudden $5 \mathrm{kPa}$ increase of pressure on the horizontal instruments (TEPCs $\mathrm{H} 1$ and $\mathrm{H} 2$ ), which is equivalent to $25 \mathrm{~cm}$ of backfill (hydrostatic regime). Another similar $5 \mathrm{kPa}$ spike occurs at 14:00 on 24 September. These sudden increases of pressure are an indication of the CPB flowing with 'lava' type characteristics, as previously assumed for stope 321-865-1W BLK3. Due to the 'lava-like' flowing condition, it was not possible to capture the exact time that the porewater pressure decreased for the fill fence instruments during the first pour. However, this is an indication that there is early development of shear strength.

At 14:40, the underground operators noted that paste was coming out of the indicator pipe, identifying that the brow was completely full. The valve of the indicator pipe was closed, and the pour continued. The pressure decreases after this point which indicates that the shear strength developing within the CPB was fast enough to develop an arching effect, thereby decreasing the stress transfer to the fill fence. The binder was not reduced from 9 to $3 \%$ binder until 16:30 to ensure that there was adequate amount of CPB above the brow. At 17:00 (the approximate time that the 3\% binder would be entering the stope), the fill fence instruments register a steady increase of pressure acting on the fill fence. This is an indication, as expected, that the $3 \%$ binder does not develop shear strength fast enough to prevent stress transfer through the plug to the fill fence.

Figures 10 and 11 show the instrument results for the remainder of the pour (pours two to six). Figure 10 shows the results of the in-stope instrumentation cluster, which saw an increase of 30 and $37 \mathrm{kPa}$ for the TEPC-H2 (transversal) and TEPC-H1 (longitudinal) total pressure, respectively. The vertical pressure (TEPC-V) saw a $32 \mathrm{kPa}$ increase. The smallest increase $(30 \mathrm{kPa})$ measured in the direction of the stope span/width (TEPC-H2) is attributed to the development of effective stresses, and hence the development of arching predominantly in the stope width direction.

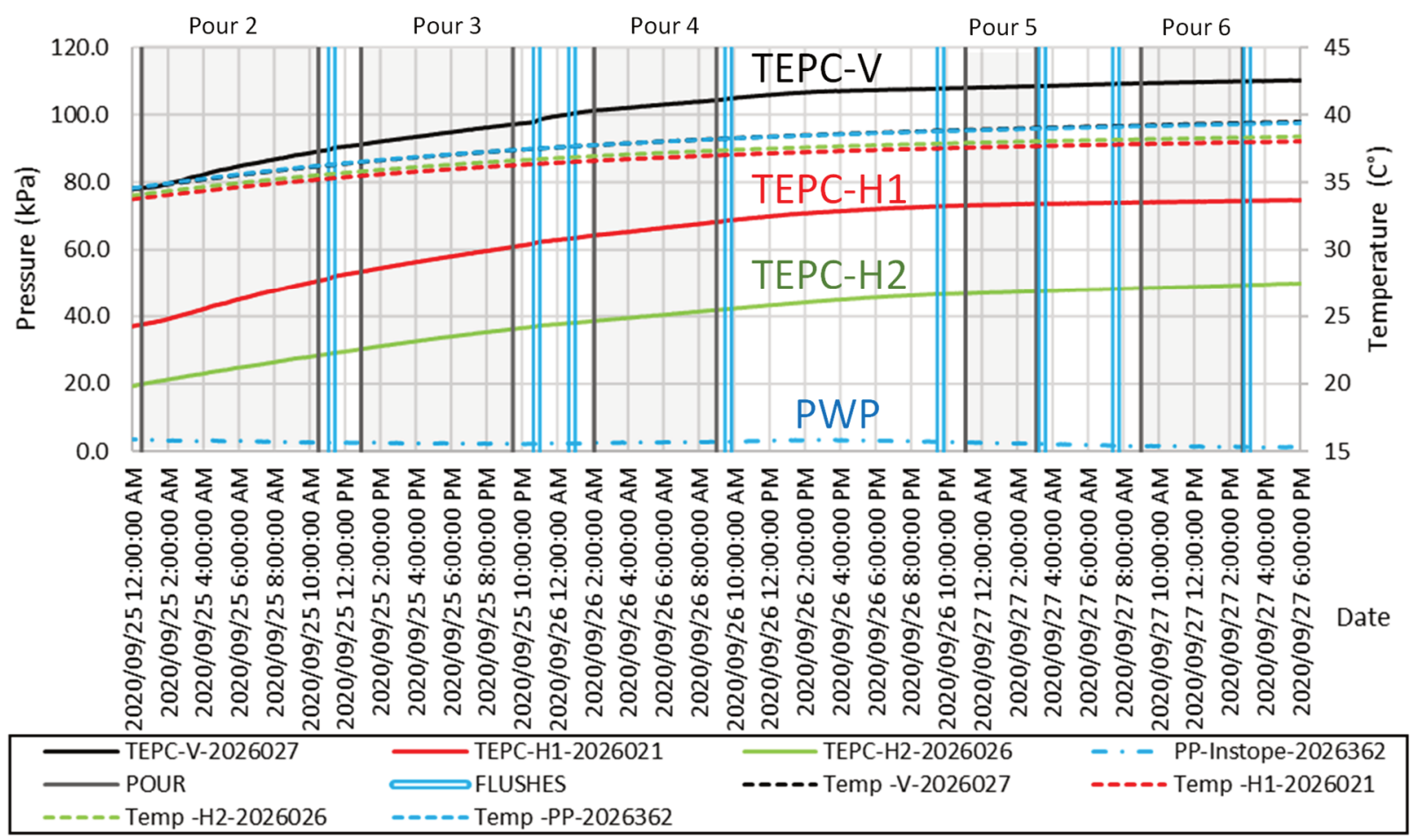

Figure 10 In-stope instrumentation cluster response for second to sixth pour of stope 512-595-1E BLK3 
Figure 11 shows the results of the fill fence instrumentation cluster, which saw a 35 and $39 \mathrm{kPa}$ increase in the TEPC-H2 and TEPC-H1 pressures, respectively. The vertical pressure, TEPC- $\mathrm{V}$, only increased by $5.0 \mathrm{kPa}$, which is equivalent to $0.28 \mathrm{~m}$ of backfill height. The space between the instruments and the back was only $0.3 \mathrm{~m}$, therefore the back and brow were shielding the potential increase in vertical pressure as the paste filled the main section of the stope. Figure 11 also shows a $7 \mathrm{kPa}$ spike of pressure for the horizontal measurements after the flush prior to the fourth pour. The piezometer (PWP) did not register any increase after the third pour flush. An additional $3 \mathrm{kPa}$ spike occurred on both horizontal measurements after the flush prior to the fourth pour. Conversely to the previous flush, the piezometer did register a $3 \mathrm{kPa}$ spike of pressure after the flush prior to the fourth pour. This is an indication that the fill fence is not completely isolated from additional loading if excess water is added to the system. The unique finding from this test stope was the recording of the highest pressure acting on the muck fence, which was $52 \mathrm{kPa}$.

It is important to note that the pore pressure measurement captures a negative reading. This negative reading could be caused by the water pressure dropping below the original ambient air pressure. This result is an indication that effective stresses are increasing.

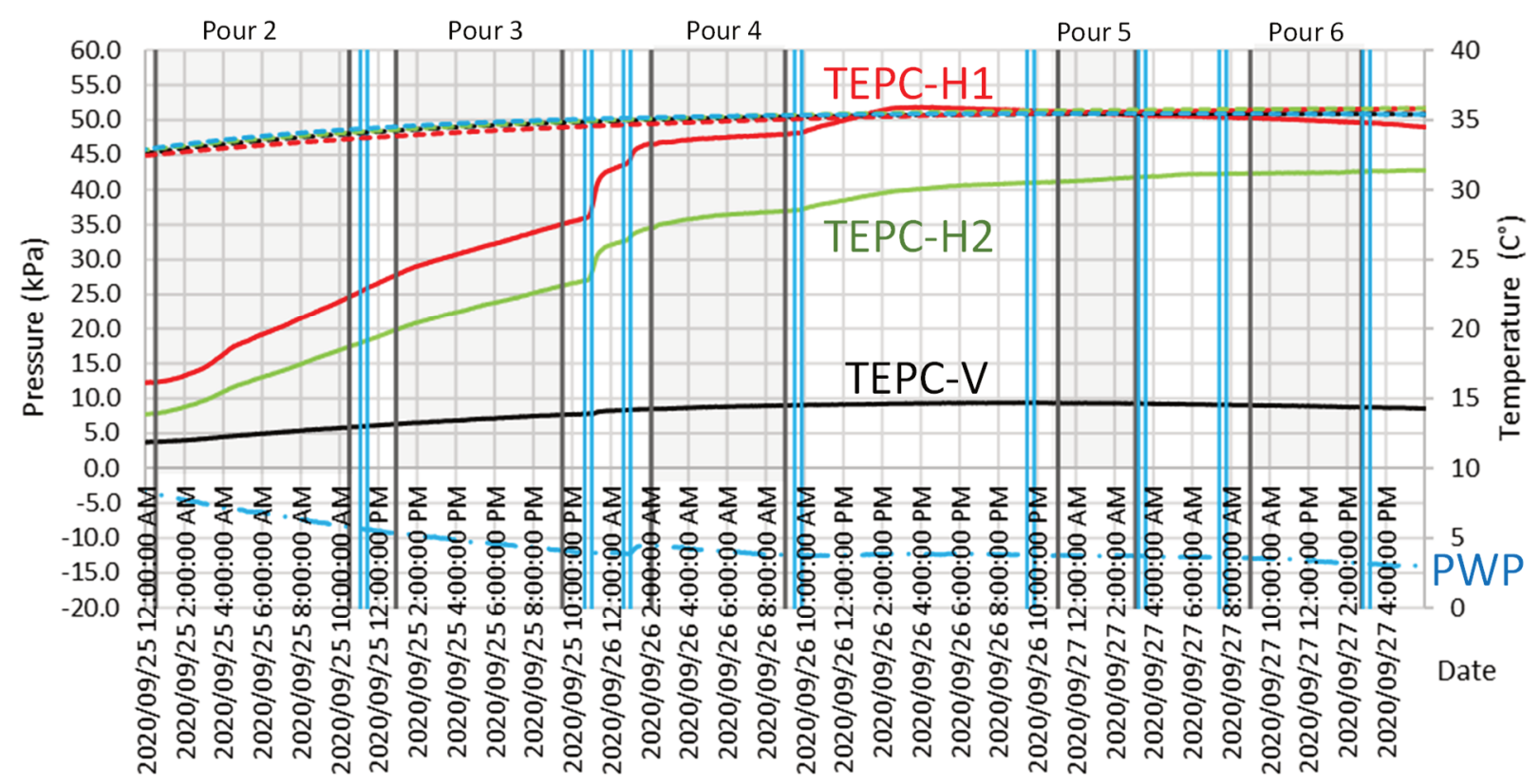

\begin{tabular}{|c|c|c|c|}
\hline $\begin{array}{l}\text { TEPC-V-2026022 } \\
\text { POUR } \\
- \text { - Temp -H2-2026023 }\end{array}$ & $\begin{array}{l}\longrightarrow \text { TEPC-H1-2026020 } \\
\text { FLUSHES } \\
=\text { - Temp -PP-2026365 }\end{array}$ & $\begin{array}{l}\text { TEPC-H2-2026023 } \\
--- \text { - Temp -V-2026022 }\end{array}$ & $\begin{array}{l}- \text { - PP-Barricade-2026365 } \\
- \text { - Temp -H1-2026020 }\end{array}$ \\
\hline
\end{tabular}

Figure 11 Fill fence instrumentation cluster response for second to sixth pour of stope 512-595-1E BLK3

\subsection{Stope 192-979-1E BLK4}

Stope 192-979-2E BLK4 was the fourth stope being tested during the monitoring program at RLO, the second to be tested on the arched rebar fence, and the second to be poured with $9 \%$ binder ( $41 \%$ class $C$ fly ash, $\sim 59 \%$ cement) for the plug region. Stope 192-979-2E BLK4 is $20 \mathrm{~m}$ high, 12-14 m long, and typically 3.0-4.3 $\mathrm{m}$ wide (max $5.8 \mathrm{~m}$ wide within bottom drift) from HW to $\mathrm{FW}$ with a dip of $\sim 72^{\circ}$. The arched rebar fence was constructed in a drift that is approximately $4.7 \mathrm{~m}$ wide and $4.4 \mathrm{~m}$ high. The rebar fence was positioned $\sim 4 \mathrm{~m}$ from the brow. The total time and pour time required for the stope were 65 and 36 hours, respectively.

The unique finding from this stope was that it had the highest tested pressure on the rebar fence. The high pressure was attributed to thermal expansion. No evidence was shown that the high pressure was associated with seismic events or wall closures. An additional unique finding was that excessive flushing led to porewater pressure spikes. The detailed instrumentation results of this test stope are presented in Oke et al. (2021). 


\subsection{Summary of test program and implementation}

A detailed summary of each of the test stopes is summarised in Table 3. Table 3 provides the peak TEPC-H1 measured pressure for both the in-stope cluster and the fill fence cluster. Additionally, the peak TEPC-H1 pressure immediately following the completion of the plug pour region is recorded. In comparing these pressures, it is obvious to see that the pressure acting on the barricade is less than the in-stope pressure. This reduction of pressure is caused by the brow (stress shadowing) and internal arching, which was previously observed during works done by Thompson at al. (2009). As stated in Section 2, the maximum allowable pressure of the arched rebar fence was $86 \mathrm{kPa}$, depending on drift span. The measured pressures on the fill fences indicate that at the end of the plug pour region, the fill fences were only experiencing a maximum of $34 \%$ of the allowable pressure. By the end of the pour, the pressure acting on the barricade was less than the allowable pressure. The pressure did exceed the allowable pressure for Stope 192-979-1E BLK4; however, this occurred six days after the pour had completed and is attributed to thermal expansion.

Table 3 Summary of RLO test results. Notes: ${ }^{1}$ denotes final pressure acting on $\mathrm{H} 1$ instruments, ${ }^{2}$ denotes pressure acting on $\mathrm{H} 1$ instruments at end of plug pour, $\mathrm{H} 1$ denotes horizontal pressure acting on the fill fence or in the direction perpendicular to the fill fence, ${ }^{3}$ measured time within the brow or at the fill fence

\begin{tabular}{|c|c|c|c|c|c|c|c|c|c|}
\hline $\begin{array}{l}\stackrel{0}{0} \\
\dot{0}\end{array}$ & 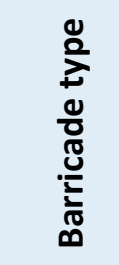 & 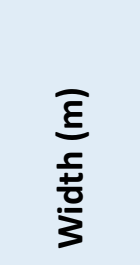 & 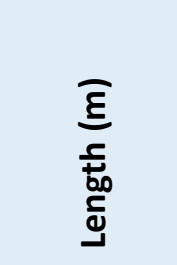 & 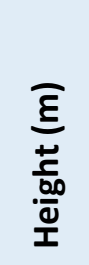 & 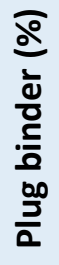 & 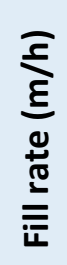 & 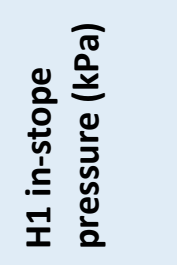 & 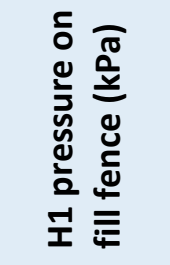 & 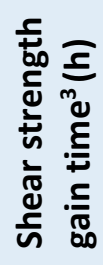 \\
\hline 321-865-1W BLK3 & $\begin{array}{l}\text { Muck } \\
\text { fence }\end{array}$ & 3.0 & 23.5 & 16.4 & 5 & 0.4 & ${ }^{1} 53^{2} 18$ & ${ }^{1} 24{ }^{2} 8$ & $\sim 2$ \\
\hline 260-876-1 BLK 1 & $\begin{array}{l}\text { Rebar } \\
\text { fence }\end{array}$ & $2.4-3.4$ & $22.7-26.5$ & 20.6 & 5 & 0.3 & ${ }^{1} 80^{2} 35$ & ${ }^{1} 44^{2} 15$ & $\sim 4$ \\
\hline 512-595-1E BLK3 & $\begin{array}{l}\text { Muck } \\
\text { fence }\end{array}$ & $3.4-5$ & $13-21$ & 24 & 9 & 0.3 & ${ }^{1} 75^{2 \sim 25}$ & ${ }^{1} 52^{2 \sim 5}$ & $\sim 3$ \\
\hline 192-979-1E BLK4 & $\begin{array}{l}\text { Rebar } \\
\text { fence }\end{array}$ & $3.0-4.3$ & $12-14$ & 20 & 9 & 0.3 & ${ }^{1} 142^{2 \sim 33}$ & ${ }^{1} 112^{2 \sim 30}$ & $\sim 5$ \\
\hline
\end{tabular}

From the results of this study, it was found that the pressure recorded acting on the fill fence and within the stope was typical or less than typical by the end of the pour compared to other continuous pour measurements, which are summarised in Oke \& Hashemi (2021). These lower than typical values indicate that the CPB behaviour is sufficient for a continuous pour regime at RLO. The results did find the highest pressure recorded acting on a fill fence during a continuous pour, when compared to other continuous pours as summarised in Oke \& Hashemi (2021). However, this high pressure occurred after the pour was finished and was presumably caused by thermal expansion, and thus does not pose any safety risk. Therefore, RLO can transition to a continuous pour regime with proper safety protocols and within similar geometric and filling regime of the test stopes. Safety protocols consist of:

- Routine quality assurance/quality control of CPB sampling methods (slump tests, UCS tests, moisture samples).

- Routine quality assurance/quality control on fence installation and piping installation.

- Early-age (18 hour) CPB strength testing.

- Camera or in-person monitoring of fill fences and CPB placement.

- Exclusion zones. 
Even though the study shows that RLO can transition to a continuous pour safely, an exclusion zone is still required during the pour. RLO has found that for typical operating conditions at site, the exclusion zones required for continuous pouring would impede operations. An alternative optimisation was proposed based on the results of the study (when continuous pours cannot be implemented due to operational constraints). RLO can implement a slightly less aggressive pouring strategy by requiring a five-hour shutdown at the end of each backfilling shift until the plug has been completed (pre-study typical pouring conditions). This allows for the paste to gain sufficient shear strength to resist liquefaction and reduce the exclusion zone sizes and the time requirement until the exclusion zones can be removed.

\section{Conclusion}

At RLO, the previous conservative cure time of the CPB resulted in the need to transfer back and forth between two stopes to ensure constant placement of paste backfill. This pour regime resulted in operational delays and inefficiencies. The result of this study indicates that a more aggressive pour can be safely conducted at RLO with proper additional safety protocols in place because of the following:

- Measured barricade pressures were comparable or lower by the end of the plug pour than continuous pour measurements taken at other sites that have implemented continuous pouring.

- Measured barricade pressures were $\sim 1 / 3$ of the allowable fill fence pressure at the end of the plug pour.

- Typical CPB plug strength resisted liquefaction relatively quickly (i.e. within the time to fill the plug region):

○ $9 \%$ binder by 17 hours.

- $5 \%$ binder by 20 hours.

- Exclusion zones have been designed based on the potential volume of paste that is not able to resist liquefaction.

RLO should be able to reduce their cure times from 36-72 hours, down to five hours (shutdown during shift change/blast time during plug pour). RLO have chosen not to move towards a continuous pour (no stops during the entire stope pour) until they have automation capabilities (flushing, pressure gauges, etc.) to remove the underground worker from the area (i.e. maintaining a safe exclusion zone). It would be prudent for RLO to verify the fill fence shear strength: (i) internal shear strength, and (ii) frictional resistance to establish safe design criteria (i.e. an acceptable Factor of Safety for the fill barricade). This will enable RLO to conduct a safe continuous CPB operation.

\section{Acknowledgement}

The authors would like to thank the Red Lake operation of Evolution Mining Management Team and Evolution Leadership Team for allowing them to publish this study. We would also like to thank the Evolution Production Team in assisting us with the logistics and placement of instrumentation in order to obtain the invaluable information.

\section{References}

Belem, T, Effenguet, H \& Mbonimpa, M 2013, 'Estimation of required minimum binder content by assessing the liquefaction potential of early age cemented mine backfill', Proceedings of the 66th Canadian Geotechnical Conference, The Canadian Geotechnical Society, Vancouver.

Grabinsky, MW, Simon, D, Thompson, BD, Bawden, WF \& Veenstra, RL 2014, 'Interpretation of as-placed cemented paste backfill properties from three mines', in Y Potvin \& T Grice (eds), Proceedings of the Eleventh International Symposium on Mining with Backfill, Australian Centre for Geomechanics, Perth, pp. 351-363, https://doi.org/10.36487/ACG_rep/1404_28_Grabinsky

Grice, T 1998, 'Underground mining with backfill', Proceedings of the 2nd Annual Summit - Mine Tailings Disposal Systems.

Le Roux, K, Bawden, WF \& Grabinsky, MW 2004, 'Liquefaction analysis of early age cemented paste backfill', Proceedings of the 8th International Symposium on Mining with Backfill, The Nonferrous Metals Society of China, Beijing, pp. 233-241. 
Oke, J \& Hashemi, A 2021, 'In-situ backfill monitoring database', in AB Fourie \& D Reid (eds), Paste 2021: Proceedings of the 24th International Conference on Paste, Thickened and Filtered Tailings, Australian Centre for Geomechanics, Perth, pp. 353-368.

Oke, J, Hawley, K, Belem, T \& Hashemi, A 2021, 'Paste backfill thermal contraction: Red Lake operations case study', in AB Fourie \& D Reid (eds), Paste 2021: Proceedings of the 24th International Conference on Paste, Thickened and Filtered Tailings, Australian Centre for Geomechanics, Perth, pp. 381-396.

Theriault, JA, Frostiak, J \& Welch, D 2003, 'Surface disposal of past tailings at the Bulyanhulu gold mine, Tanzania', in G Spiers, P Beckett \& H Conroy (eds), Proceedings of the 2003 Sudbury Mining and Environment Conference, Laurentian University Centre for Continuing Education, Sudbury, pp. 265-269.

Thompson, BD, Grabinsky, MW, Bawden, WF \& Counter, DB 2009, 'In-situ measurements of cemented paste backfill in long-hole stopes', in M Diederichs \& G Grasselli (eds), Proceedings of the 3rd Canada-US Rock Mechanics Symposium \& 20th Canadian Rock Mechanics Symposium, University of Toronto Press, Toronto.

Yumlu, M 2001, Backfill Practices at Çayeli Mine, Proceedings of the 17th International Mining Conference, pp. 333-339. 
